\title{
Dynamic Response of Rub Caused by a Shedding Annular Component Happening in a Steam Turbine
}

\author{
J. M. Chen, D. X. Jiang, N. F. Wang, and S. P. An \\ State Key Laboratory of Control and Simulation of Power System and Generation Equipment, Department of Thermal Engineering, \\ Tsinghua University, Beijing 100084, China
}

Correspondence should be addressed to J. M. Chen; cjm10@mails.tsinghua.edu.cn

Received 20 January 2015; Accepted 4 May 2015

Academic Editor: Mickaël Lallart

Copyright (C) 2015 J. M. Chen et al. This is an open access article distributed under the Creative Commons Attribution License, which permits unrestricted use, distribution, and reproduction in any medium, provided the original work is properly cited.

Rub caused by a shedding annular component is a severe fault happening in a steam turbine, which could result in a long-term wearing effect on the shaft. The shafting abrasion defects shortened the service life and damaged the unit. To identify the fault in time, the dynamic response of rub caused by a shedding annular component was studied as follows: (I) a rotor-bearing model was established based on the structural features of certain steam turbines; node-to-node contact constraint and penalty method were utilized to analyze the impact and friction; (II) dynamic response of the rotor-bearing system and the shedding component was simulated with the development of rub after the component was dropping; (III) fault features were extracted from the vibration near the bearing position by time-domain and frequency-domain analysis. The results indicate that the shedding annular component would not only rotate pivoting its axis but also revolve around the shaft after a period of time. Under the excitation of the contact force, the peak-peak vibration fluctuates greatly. The frequency spectrum contains two main components, that is, the working rotating frequency and revolving frequency. The same phenomenon was observed from the historical data in the field.

\section{Introduction}

Rub is a common fault happening in rotating machinery. Big vibration and abrasion induced by rub would shorten the life of machine and even threaten the safety of operation. Therefore, the dynamic characteristics of rub attract many investigators to study.

There are many different types of rub classified by reasons and damaged part. Rotor-to-stator rub is one of the most usual types, which have been studied in a lot of literatures. Jeffcott rotor is the simplest rotor-bearing system, which was used to simulate the nonlinear phenomenon by Choy and Padovan [1]. Chu and Zhang [2] acquired the periodic, quasiperiodic, and chaotic vibration of a rub-impact Jeffcott rotor. The nonlinear phenomenon was validated by experiments in the later literature [3]. The axial degree of freedom is considered in the research of An et al. [4]. The chaotic vibration of a rub-impact rotor was simulated under axial thrust. Kellenberger [5] considered frictional heating in his Jeffcott model. A spiral vibration was observed in the interaction between rotor and stator. Childs [6] revised
Kellenberger's model by considering the angle between the thermal bowing direction and the impact force.

In order to study the dynamics of the shafting, transfer matrix method and finite element method were applied to analyze the rotor-to-stator rub. Qin et al. [7] constructed a multielement system to simulate the dynamics of a rubimpact overhung rotor based on transfer matrix method. This method was also used by Huang et al. [8,9] to analyze the stability of thermal-induced vibration in a rub-impact rotor. Schmied [10] studied the rub between rotor and steam seals in a steam turbine using finite element method. Onedimensional model with multidisk and multijournal was established in the rub problem. Muszynska et al. [11, 12] revealed thermal/mechanical effect of rotor-to-stator rubs by a 1-dimensional finite element model. Bachschmid et al. [13] proposed a 3-dimensional finite element model to simulate the spiral vibration of rub-impact rotor, which was well validated by the experiment results.

Comparing with rotor-to-stator rub, the rub caused by a shedding component is less usual in the field. Nevertheless, the damage of this type of rub is much severer, usually 


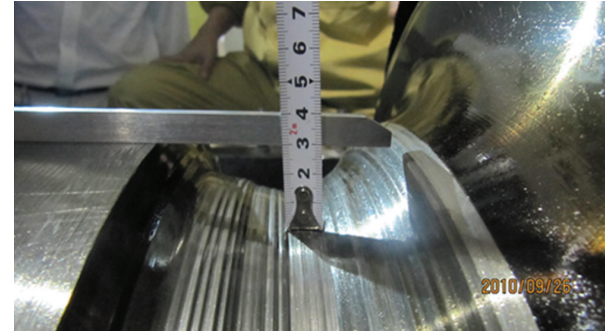

FIgURE 1: Worn groove of the LP rotor.

with severe wear and abrasion accompanied. A $660 \mathrm{MW}$ low pressure cylinder (LP) rotor was badly abraded by the shedding of the side plate of the coupling guard [14]. The worn groove of the shaft was $10.1 \mathrm{~mm}$ wide and $15.2 \mathrm{~mm}$ deep. The same problem bothered another steam turbine unit [15]. The problem was not discovered until the unfolding cylinder in an overhaul, which results in an $80 \mathrm{~mm}$ wide and $28.8 \mathrm{~mm}$ deep worn groove. The abrasion greatly threatened the safety of the steam turbine and repairing of the LP rotor was utilized to reduce the stress concentration [16]. In order to identify the fault in time, it is significant to study the dynamic response of the rub caused by a shedding annular component.

The worn LP rotor in [15] was from a supercritical steam turbine unit. The worn groove located on the shaft neck, which was $319 \mathrm{~mm}$ away from the coupling end, seen as in Figure 1. The worn groove was generated by the rub between the shaft and a shedding side plate, which is separated from the coupling guard.

In this paper, the case in [15] was studied. Based on finite element method, the dynamic model of rub caused by a shedding annular component was established. The transient analysis was conducted and the motion of the shafting and the shedding component were simulated. The results were well validated by the historical data and typical fault features were extracted from the analysis.

\section{Methods}

2.1. The Structure of the Steam Turbines. The steam turbine unit where the rub happens is a supercritical steam turbine unit. The scheme of the shafting is showed in Figure 2. Location of the wearing is close to Bearing \#3, which is between the high intermediate pressure (HIP) cylinder and the low pressure (LP) cylinder.

The shedding annular component is from side plate of the coupling guard, which is a welded structure, showed in Figure 3. The excitation of the blowing air generates fatigue crack at the root of the side plate and finally the side plate falls apart from the coupling guard and impact on the shaft neck of the LP rotor.

\subsection{Dynamics Model}

2.2.1. Rotor Model. Finite element method was applied to establish the rotor model. Shafting of the steam turbines could be simplified as several shaft segments. Timoshenko beam

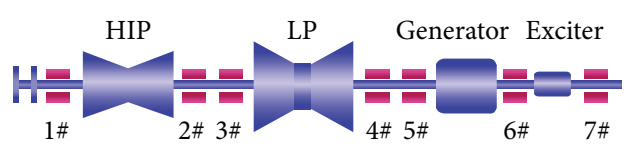

Figure 2: Scheme of the shafting.

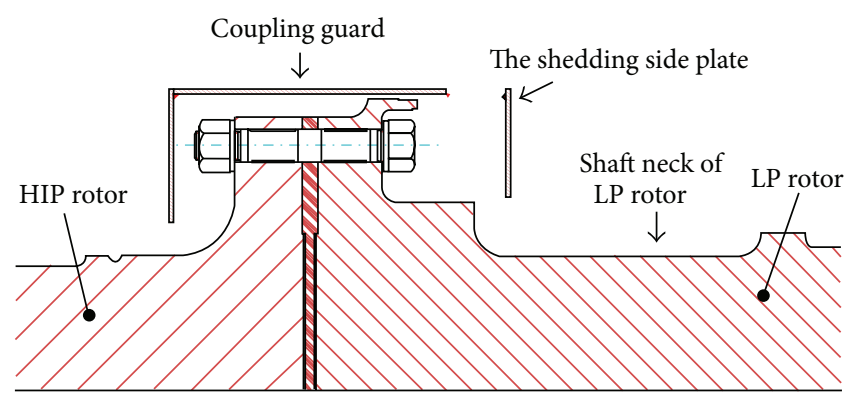

FIGURE 3: Structure of the coupling guard.

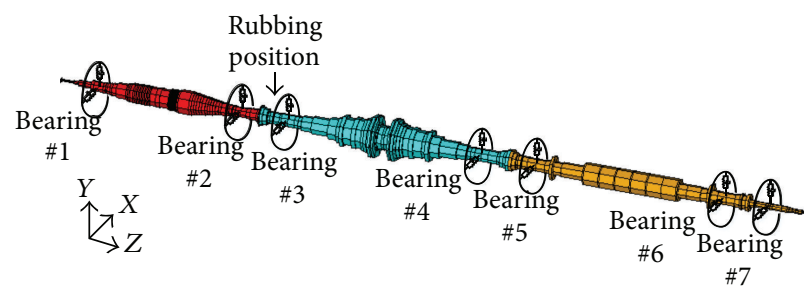

FIGURE 4: Finite element model of the shafting.

element was used for the shafting; lumped mass element was used for the blades; spring damper element was used for the journal bearing. Therefore, the rotor model was showed in Figure 4.

2.2.2. Contact Condition. The shedding annular component could be regarded as a lumped mass, which includes three DOFs (degrees of freedom), that is, UX (translational DOF in horizontal direction), UY (translational DOF in vertical direction), and ROTZ (rotational DOF via the axis).

The inner surface of the shedding annular component rubs with the shaft neck of the LP rotor. Figure 5 shows the schematic motion, where $O$ is the original point in the absolute coordinate system. $O_{1}$ is the center of the shaft at the rubbing plane, $\mathrm{O}_{2}$ is the center of the shedding component, and $P_{1}$ and $P_{2}$ are, respectively, rubbing points in the rotor surface and the inner surface of the shedding component. Natural coordinate system is constructed at point $P_{1}\left(P_{2}\right)$, where $\vec{n}$ is the normal unit vector, $\vec{\tau}$ is the tangential unit vector, and $\vec{\omega}$ is the unit angular velocity in the counterclockwise direction. They satisfy the equation $\vec{\tau}=$ $\vec{\omega} \times \vec{n} . \dot{\theta}_{2}$ is the angular velocity of the shedding annular component. $\vec{\delta}_{1, p}$ is the displacement vector of the rotor center at the rubbing plane. $\vec{\delta}_{2}$ is the displacement vector of the shedding component. 


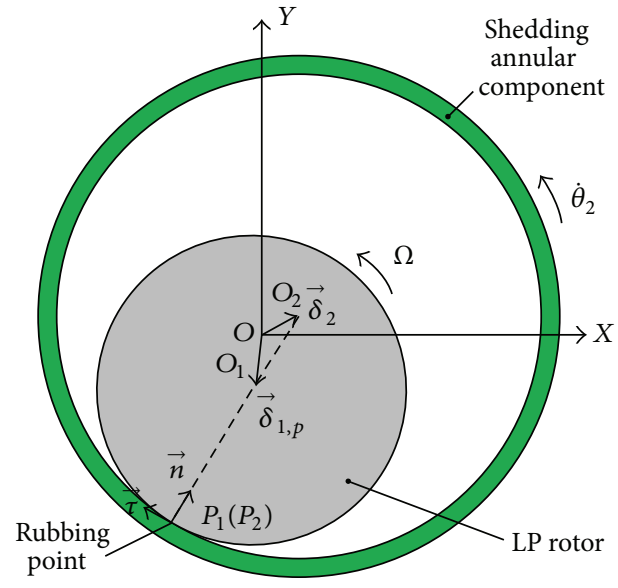

FIGURE 5: Schematic motion of the rotor and the shedding annular component.

Node-to-node contact constraint was utilized. Contact constraint condition can be written as

$$
\left|\vec{\delta}_{1, p}-\vec{\delta}_{2}\right| \leq \varepsilon
$$

in which $\varepsilon$ is the radial gap, which represents the maximum allowable distance projected on the cross-section.

2.3. Solution Method. The motion vector set of the shafting at every node satisfies the motion equation as follows:

$$
\begin{gathered}
\mathbf{M}\left\{\ddot{\vec{\delta}}_{1}\right\}+(\mathbf{C}+\Omega \mathbf{G})\left\{\dot{\vec{\delta}}_{1}\right\}+\mathbf{K}\left\{\vec{\delta}_{1}\right\} \\
=\left\{\vec{F}_{0}\right\}+\left\{\vec{F}_{\tau}\right\}+\left\{\vec{F}_{n}\right\},
\end{gathered}
$$

where $\left\{\vec{\delta}_{1}\right\}$ is the translational motion vector set at every node, $\mathbf{M}$ is the mass matrix, $\mathbf{C}$ is the damping matrix, $\mathbf{G}$ is the gyroscopic matrix caused by gyroscopic effect, $\mathbf{K}$ is the stiffness matrix, $\Omega$ is the rotational speed of the rotor, $\left\{\vec{F}_{0}\right\}$ is the harmonic excitation due to unbalance in the normal condition, $\left\{\vec{F}_{\tau}\right\}$ is the frictional force vector due to rub, and $\left\{\vec{F}_{n}\right\}$ is the normal contact force vector due to rub.

Pure penalty method and Coulomb Friction Law were implemented in the contact algorithm as follows:

$$
\begin{aligned}
& \vec{F}_{n}= \begin{cases}0, & \left|\vec{\delta}_{1, p}-\vec{\delta}_{2}\right|<\varepsilon \\
k\left(\left|\vec{\delta}_{1, p}-\vec{\delta}_{2}\right|-\varepsilon\right) \vec{n}, & \left|\vec{\delta}_{1, p}-\vec{\delta}_{2}\right| \geq \varepsilon,\end{cases} \\
& \vec{F}_{\tau}=-\mu_{s}\left|\vec{F}_{n}\right| \operatorname{sgn}\left(\vec{v}_{p 1} \cdot \vec{\tau}-\vec{v}_{p 2} \cdot \vec{\tau}\right) \vec{\tau},
\end{aligned}
$$

where $k$ is the contact stiffness, $\mu_{s}$ is the frictional coefficient, the direction of $\vec{F}_{\tau}$ is based on the tangential relative velocity of both contact bodies at the rubbing point, and $\vec{v}_{P 1}$ and $\vec{v}_{P 2}$ are, respectively, the velocity of the rotor and the shedding component at the rubbing point:

$$
\begin{aligned}
& \vec{v}_{P 1}=\dot{\vec{\delta}}_{1, p}+\Omega \vec{\omega} \times \overrightarrow{O_{1} P_{1}}, \\
& \vec{v}_{P 2}=\dot{\vec{\delta}}_{2}+\dot{\theta}_{2} \vec{\omega} \times \overrightarrow{\mathrm{O}_{2} P_{2}} .
\end{aligned}
$$

The motion equation of the shedding annular component is presented as

$$
\begin{aligned}
m_{2} \ddot{\vec{\delta}}_{2} & =m_{2} \vec{g}-\vec{F}_{\tau}-\vec{F}_{n}, \\
J_{2} \ddot{\theta}_{2} & =-\operatorname{sgn}\left(\vec{F}_{\tau} \cdot \vec{\tau}\right)\left|\overrightarrow{O_{2} P_{2}}\right|\left|\vec{F}_{\tau}\right|,
\end{aligned}
$$

where $m_{2} \vec{g}$ is the gravity.

Equations (2)-(7) were derived by Newmark- $\beta$ method. Therefore, dynamic response of the rub caused by a shedding annular component was simulated.

\section{Results and Discussion}

3.1. Dynamics of the Shedding Annular Component. Dynamics of the shedding annular component was acquired from the simulated results. Figure 6 shows the contact status after the shedding, where " 1 " represents contact and " 0 " represents separation. In the beginning, partial rub happens and the time between every two contacts is becoming shorter with the development of rub. Finally, the partial rub develops into full annular rub.

Based on (6) and (7), the shedding annular component functions by the contact and frictional force and gravity, whose trajectory is showed in Figure 7. After several contacts with the shaft neck of LP rotor, the shedding component makes revolving motion in clockwise direction. The radius of the trajectory is the radius gap $\varepsilon$. The revolving speed is showed in Figure 8. In the full annular rub state, the revolving speed $\omega_{r}$ decreases with the development of rub and finally stays in a steady value.

Different from the revolving speed, the rotating speed $\dot{\theta}_{2}$ rises rapidly while entering the full annular rub state and then increases slowly approaching a steady value. The rotating speed and revolving speed of the shedding component are controlled by (4)-(5), (7), which approximately satisfy

$$
\frac{\varepsilon}{\left|\overrightarrow{O_{1} P_{1}}\right|} \omega_{r}+\frac{\left|\overrightarrow{O_{2} P_{2}}\right|}{\left|\overrightarrow{O_{1} P_{1}}\right|} \dot{\theta}_{2}=\Omega .
$$

3.2. Dynamics of the Rotor-Bearing System. Dynamic response of the rotor-bearing system was influenced by the contact force and frictional force. Figure 9 shows the displacement vibration of the rotor in $Y$ direction at the rubbing plane (vibration in $X$ direction got similar characteristics). From the figure, the rub results in a big vibration fluctuation after developing into the full annular rub state. Beat vibration is observed, which indicates that the frequency of the contact and frictional force is different from the working rotating frequency. The frequency is actually the revolving frequency of the shedding annular component.

With the development of the rub, the fluctuation is becoming small, which is due to the decrease of the contact force, seen as in Figure 10.

As only vibration near the bearing position could be monitored, it is more important to analyze the vibration at Bearings \#1-7, which is displayed in Figure 11. The vibration 


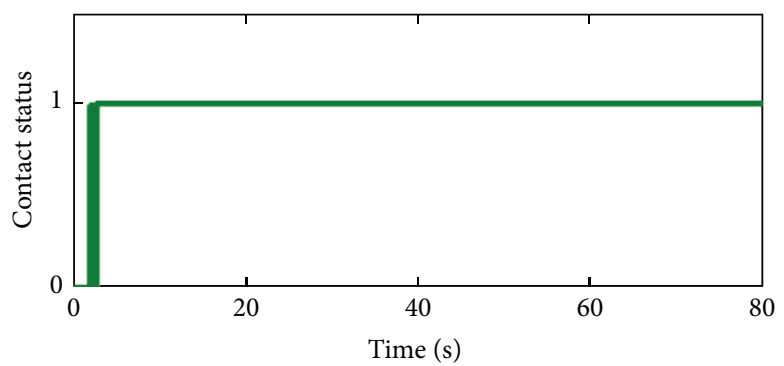

(a) $0-80 \mathrm{~s}$

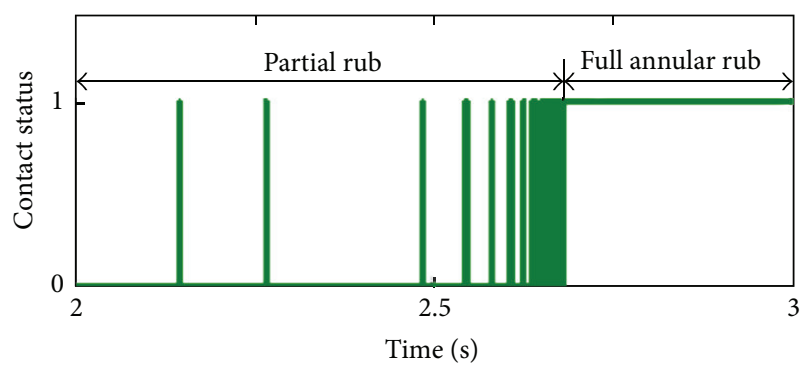

(b) $2-3 \mathrm{~s}$

Figure 6: Contact status.

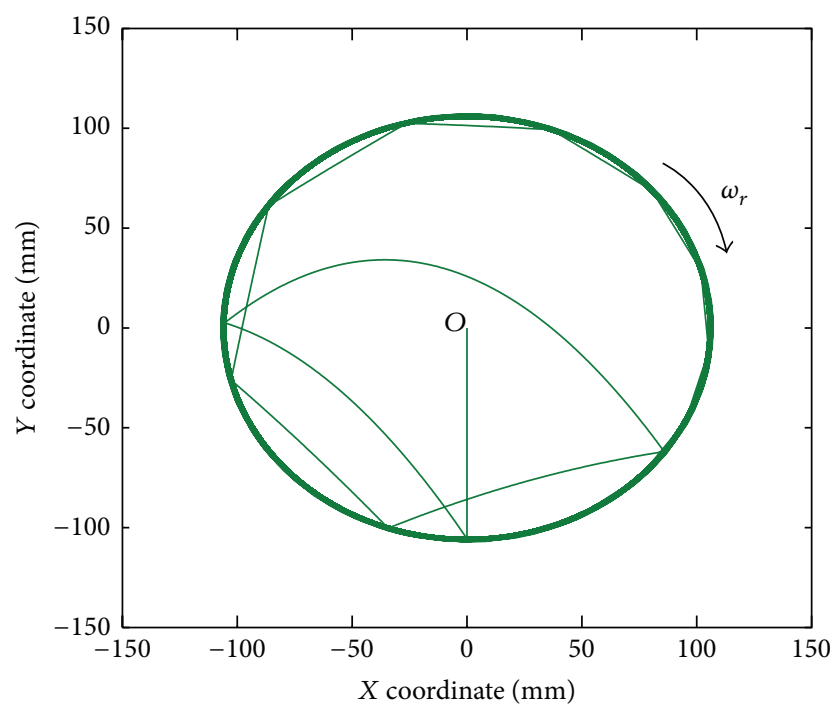

Figure 7: Trajectory of the shedding annular component.

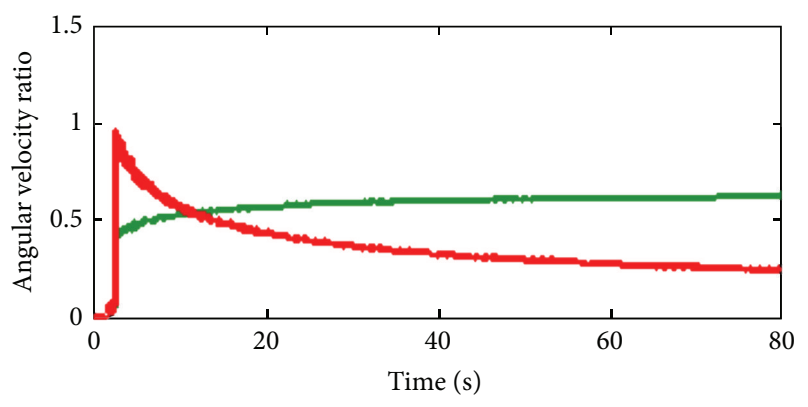

$\dot{\theta}_{2} / \Omega$

Figure 8: Rotating speed and revolving speed.

at Bearing \#3 is the most sensitive to the rub. Therefore, it is necessary to extract fault feature from the vibration at Bearing \#3.

3.3. Fault Feature and Validation. The peak-peak value of the vibration is the most useful index to evaluate the operation

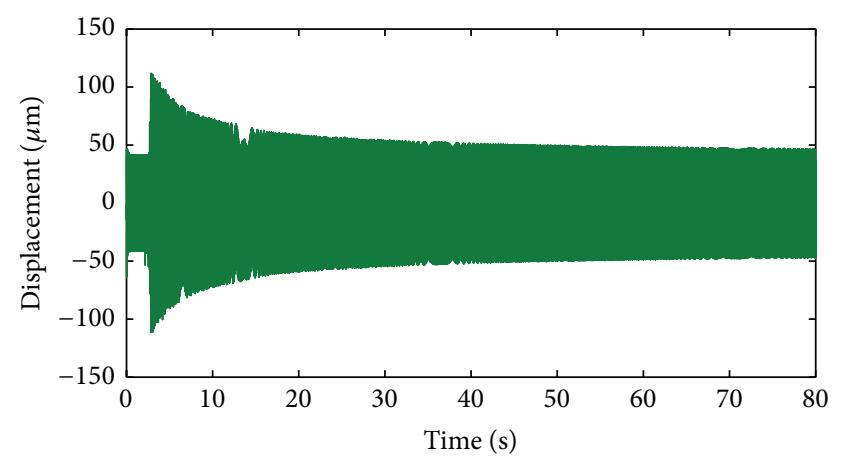

(a) $0-80 \mathrm{~s}$

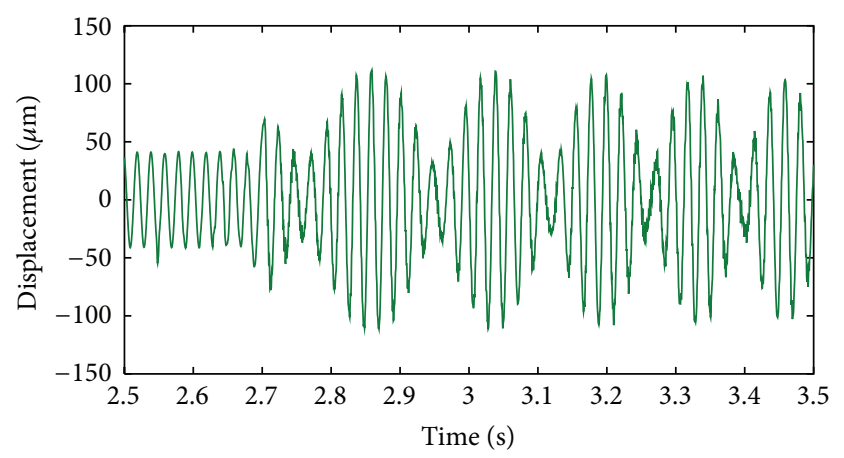

(b) $2.5-3.5 \mathrm{~s}$

FIgURE 9: $Y$ vibration of the rotor at the rubbing plane.

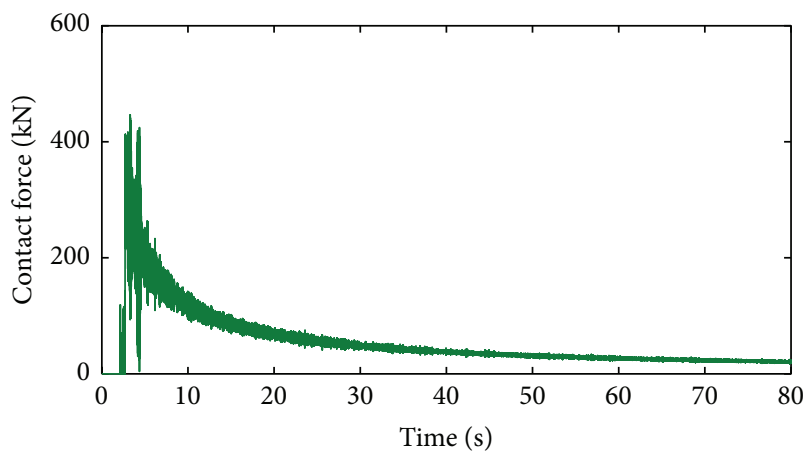

Figure 10: Contact force. 

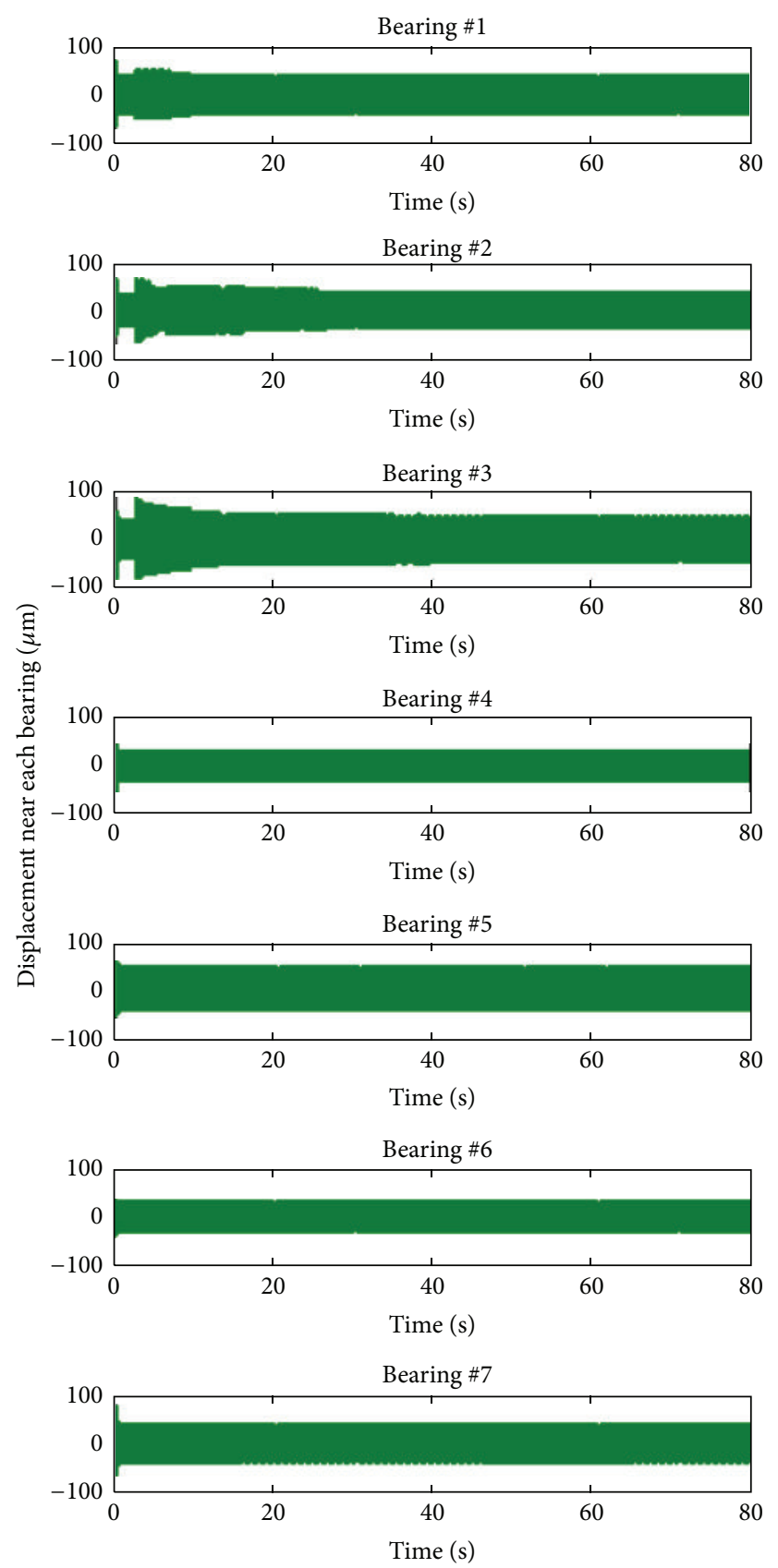

FIgURE 11: $Y$ vibration of the rotor near each bearing.

status in the field. Figure 12 shows the peak-peak value of the simulated vibration at Bearing \#3. The envelope curve indicates that a sharp fluctuation exists while entering full annular rub state. After a short period of decrease, the fluctuation amplitude reaches an extreme small value until $\omega_{r} \approx 0.5 \Omega$, which is introduced by the superposition of the vibration in $1 \mathrm{x}$ and $0.5 \mathrm{x}$ frequency. After the extreme small point, the fluctuation amplitude increases in some extent and then reduces slowly into the steady state with the development of rub.

The same phenomenon was observed based on the monitoring system of this unit, as seen in Figure 13. The

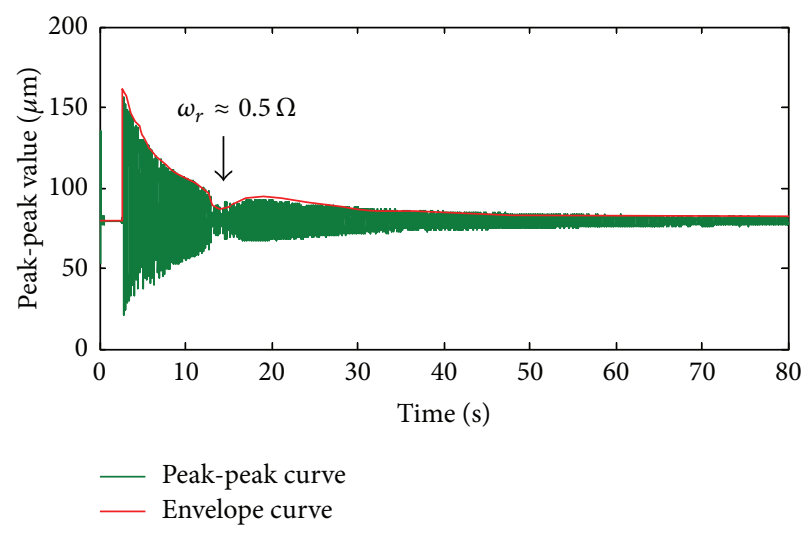

(a) $0-80 \mathrm{~s}$

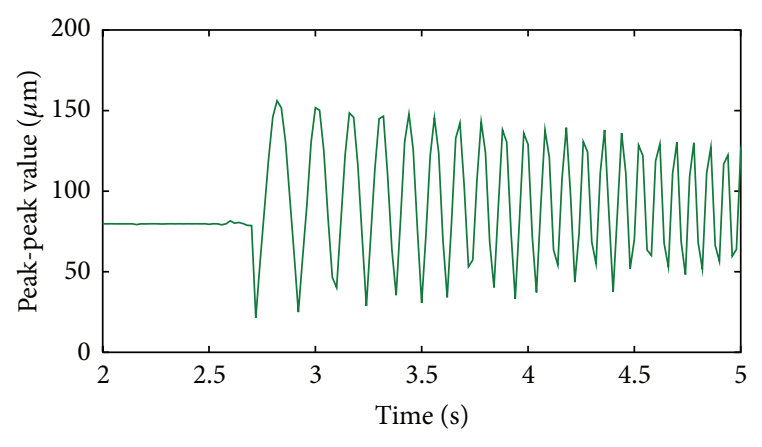

(b) $2-5 \mathrm{~s}$

FigURE 12: Peak-peak $Y$ vibration value of the rotor at Bearing \#3 (simulated).

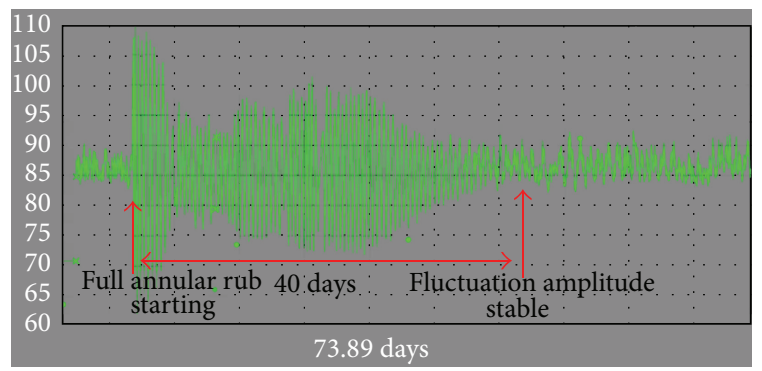

FIGURE 13: Time history of peak-peak $Y$ vibration of Bearing \#3.

fluctuation takes about 40 days to reach a relative stable state, while in the simulated results, it takes less than 80 seconds. The reason for the difference in stabilization time is that a higher frictional coefficient $\mu_{s}$ is given in the simulation. The stabilization time depends on $\mu_{s}$. However, it is impossible to simulate such a real long time in a transient analysis, because the time step should be small enough to acquire the dynamic characteristics in a revolution.

Despite the difference in stabilization time, the simulated results could reflect the dynamic feature of the rub caused by a shedding annular component in real situation. Therefore, the fault feature in the peak-peak curve is the big fluctuation.

The fault feature could also be extracted in the spectrum analysis. Figure 14 shows the spectrum waterfall of the $Y$ 


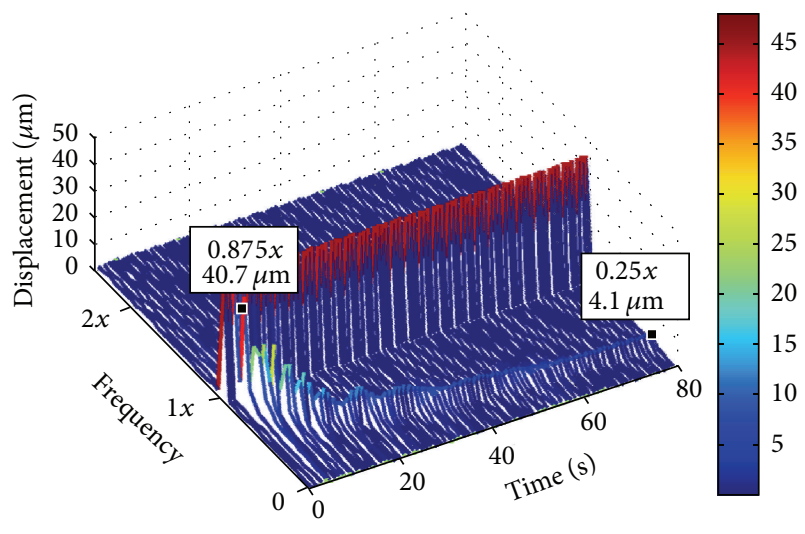

FIGURE 14: Spectrum waterfall of $Y$ vibration at Bearing \#3.

vibration at Bearing \#3. Despite the $1 \mathrm{x}$ frequency component, an extra frequency component appears after the rub happens, which changes from $0.875 \mathrm{x}$ to $0.25 \mathrm{x}$. The corresponding amplitude of the extra frequency component decreases from $40.7 \mu \mathrm{m}$ to $4.1 \mu \mathrm{m}$. The extra frequency could be regarded as a fault feature to identify the rub caused by a shedding annular component.

\section{Conclusion}

The rub caused by a shedding annular component was studied in this paper. Based on a real case, finite element method was used to establish the dynamic model of the rotor-bearing system and the shedding component. Node-tonode contact constraint condition was applied. Pure penalty algorithm and Coulomb Friction Law were utilized to control the behavior of contact and friction. As a result, the dynamic response of rub caused by a shedding annular component was simulated.

Simulated results show that the rub would develop into full annular rub and the shedding component would revolve pivoting the shaft after dropping. The contact force periodically functions on the rotor-bearing system, which results in beat vibration. As a result, a big fluctuation in peak-peak vibration and an extra decreasing frequency component in the spectrum could be observed, which could be validated by the time history data in the field. Therefore, these two fault features could be used to identify the rub caused by a shedding annular component.

\section{Conflict of Interests}

The authors declare that there is no conflict of interests regarding the publication of this paper.

\section{References}

[1] F. K. Choy and J. Padovan, "Non-linear transient analysis of rotor-casing rub events," Journal of Sound and Vibration, vol. 113 , no. 3, pp. 529-545, 1987.

[2] F. Chu and Z. Zhang, "Periodic, quasi-periodic and chaotic vibrations of a rub-impact rotor system supported on oil film bearings," International Journal of Engineering Science, vol. 35, no. 10-11, pp. 963-973, 1997.

[3] F. Chu and W. Lu, "Experimental observation of nonlinear vibrations in a rub-impact rotor system," Journal of Sound and Vibration, vol. 283, no. 3-5, pp. 621-643, 2005.

[4] X. An, J. Zhou, X. Xiang, C. Li, and Z. Luo, "Dynamic response of a rub-impact rotor system under axial thrust," Archive of Applied Mechanics, vol. 79, no. 11, pp. 1009-1018, 2009.

[5] W. Kellenberger, "Spiral vibrations due to the seal rings in turbogenerators thermally induced interaction between rotor and stator," Journal of Mechanical Design, vol. 102, no. 1, pp. 177184, 1980.

[6] D. W. Childs, “A note on Kellenberger's model for spiral vibrations," Transactions of the ASME, Journal of Vibration and Acoustics, vol. 123, no. 3, pp. 405-408, 2001.

[7] W. Qin, G. Chen, and G. Meng, "Nonlinear responses of a rubimpact overhung rotor," Chaos, Solitons and Fractals, vol. 19, no. 5, pp. 1161-1172, 2004.

[8] B. Huang, "The influence of thermal-induced bow on the rotor stability," Journal of Vibration Engineering, vol. 14, no. 1, pp. 2328, 2001.

[9] B. Huang, J. Yang, and M. Gao, "The thermal sensitivity of rubbing rotor," in Proceedings of the Chinese Society for Electrical Engineering, vol. 20, pp. 65-88, 2000.

[10] J. Schmied, "Spiral vibrations of rotors," in Proceedings of the ASME Design Technology Conferences-11th Biennial Conference on Mechanical Vibration and Noise, vol. 2, pp. 449-456, 1987.

[11] P. Goldman and A. Muszynska, "Rotor-to-stator, rub-related, thermal/mechanical effects in rotating machinery," Chaos, Solitons \& Fractals, vol. 5, no. 9, pp. 1579-1601, 1995.

[12] A. Muszynska, "Thermal/mechanical effect of rotor-to-stator rubs in rotating machinery," in Proceedings of the 14th Biennial ASME Design Technical Conference on Mechanical Vibration and Noise, vol. 60, pp. 1-6, 1993.

[13] N. Bachschmid, P. Pennacchi, and A. Vania, "Thermally induced vibrations due to rub in real rotors," Journal of Sound and Vibration, vol. 299, no. 4-5, pp. 683-719, 2007.

[14] L. Yang, M. Pi, L. Di, and Z. Zhang, "660MW supercritical steam turbine rotor wear and treatment," Power System Engineering, vol. 27, no. 5, pp. 57-58, 61, 2001.

[15] W. Zhu, X. Shen, and J. Jiang, "Vibration of fatigue analysis on pre-wear and post-wear shafting of LP rotor in a 600MW steam turbine," Mechanical Engineer, no. 12, pp. 169-170, 2013.

[16] C. Liu, D. Jiang, J. Chen, and J. Chen, “Torsional vibration and fatigue evaluation in repairing the worn shafting of the steam turbine," Engineering Failure Analysis, vol. 26, pp. 1-11, 2012. 

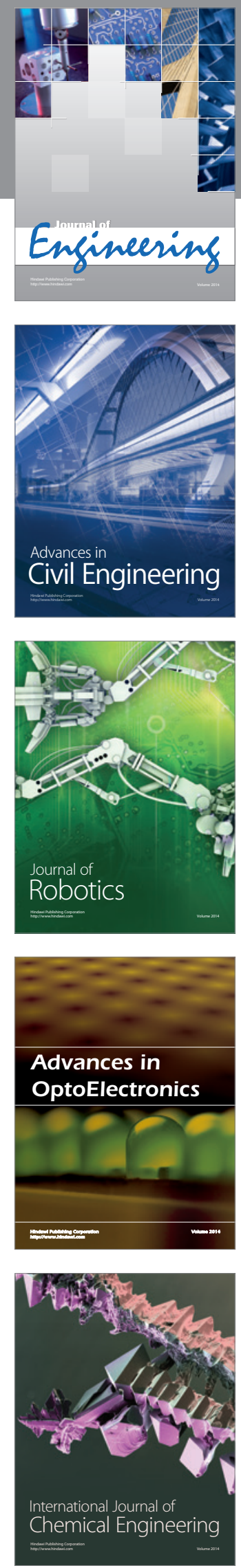

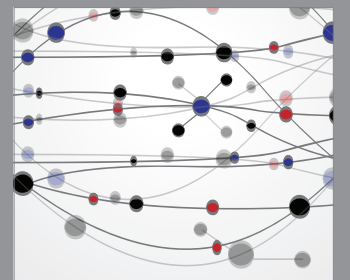

The Scientific World Journal
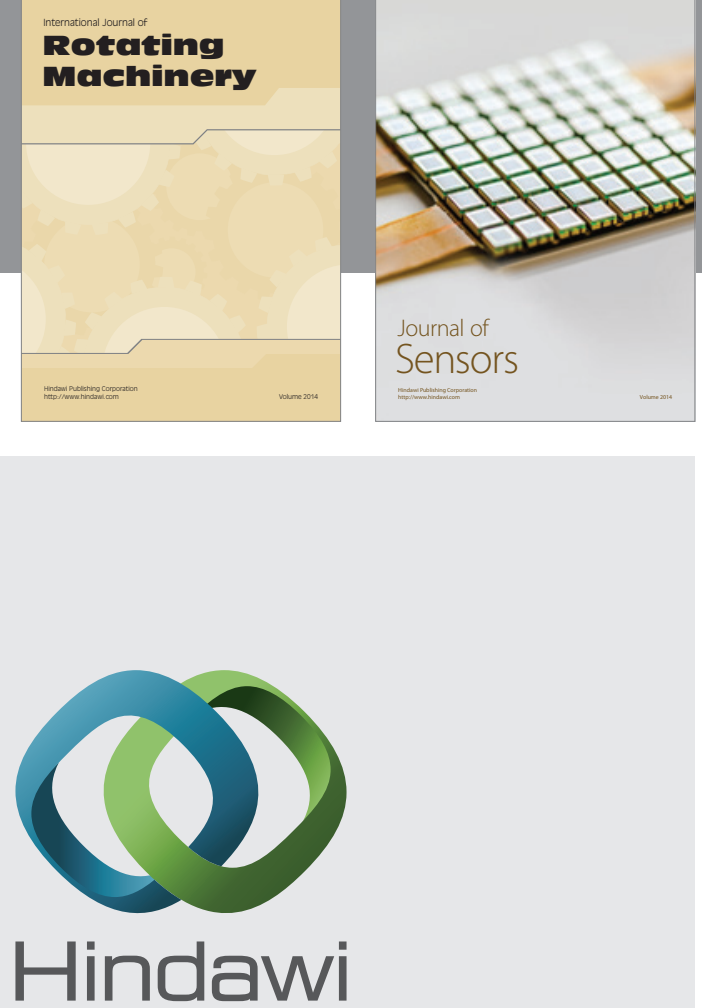

Submit your manuscripts at http://www.hindawi.com
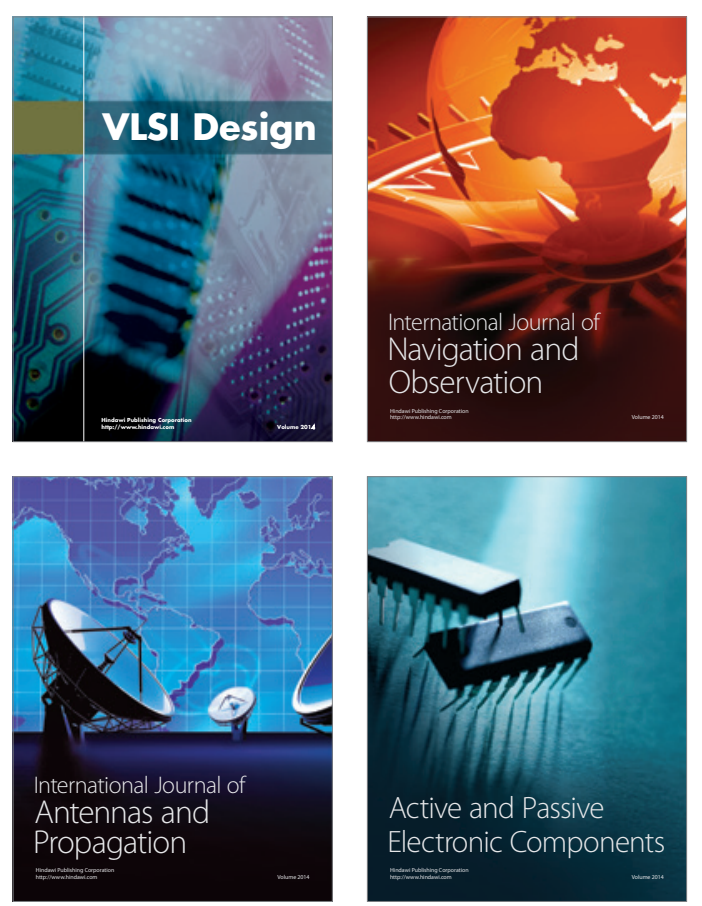
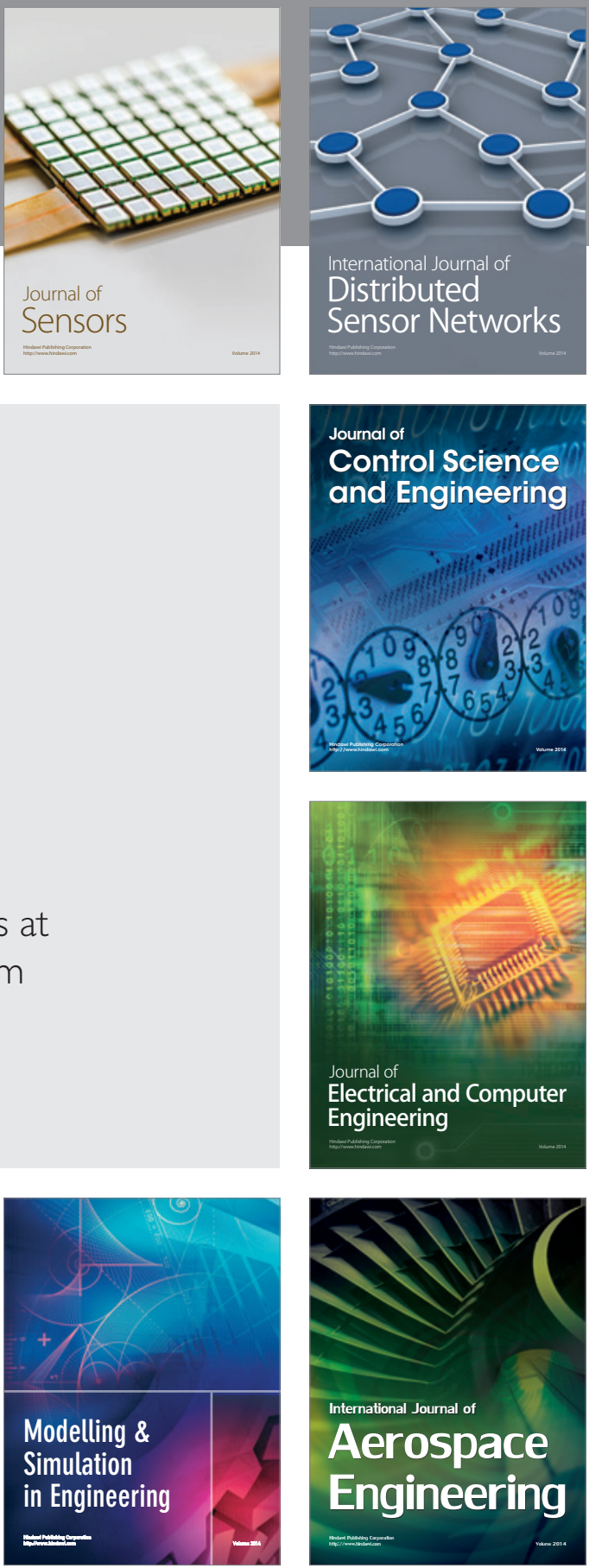

Journal of

Control Science

and Engineering
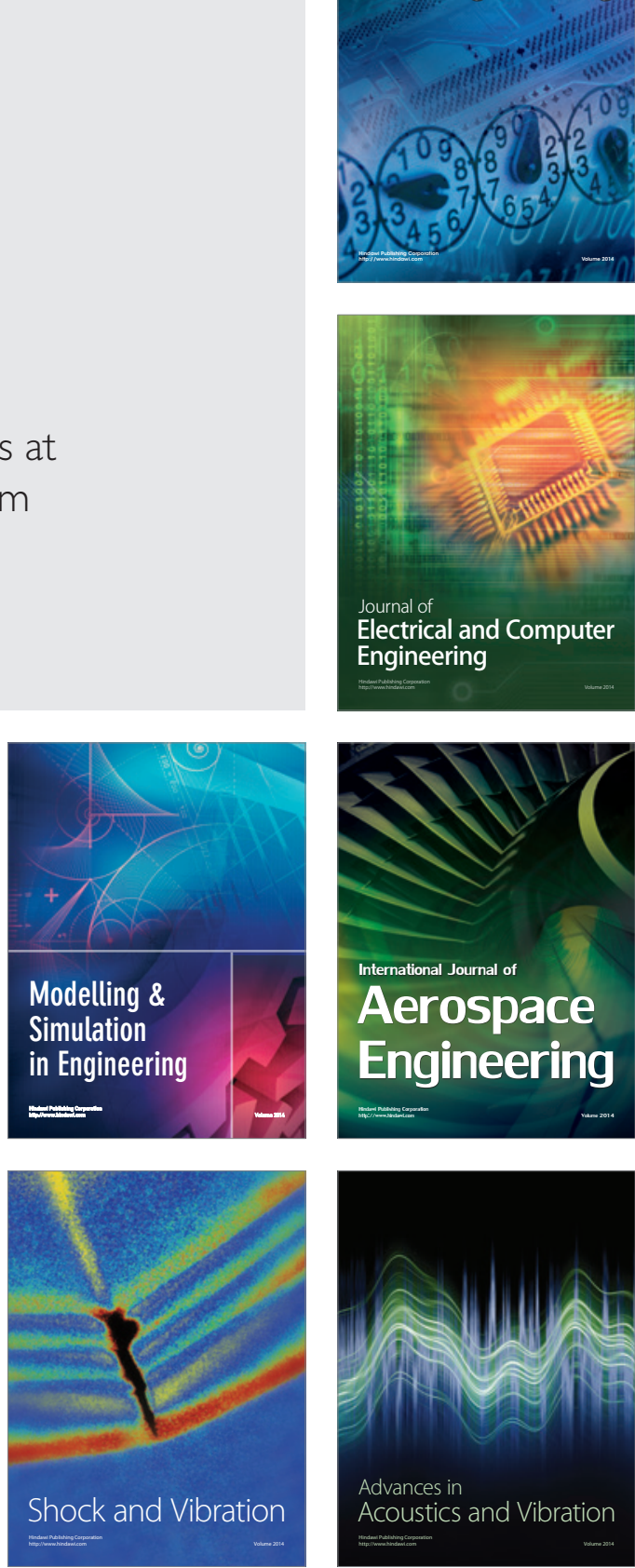